\title{
Effects of Desire to Complete Daily Steps Target using Step Detectors on Physical and Mental Health
}

\author{
Nikhil Prashant ${ }^{1}$, Aditya Prem Sharma ${ }^{2}$, Sama Udaykiran Reddy ${ }^{3}$ \\ ${ }^{1}$ Student, Lovely Professional University, Patna, India \\ ${ }^{2}$ Student, Lovely Professional University, Hyderabad, India
}

\section{Article Info}

Volume 7, Issue 3

Page Number: 33-36

Publication Issue :

May-June-2021

Article History

Accepted : 01 May 2021

Published : 05 May 2021

\begin{abstract}
This paper focuses on area which is generally regarded to have positive effects on our health but as every coin has two sides this one has too, but this coin is biased, and the negative side is regarded as unimportant. Here we have tried to explore positive and negative effects of Step Detector caused by desire to complete targets on physical and mental health of a person.
\end{abstract}

Keywords : Mental Health, Physical Selves, COVID-19, Step Detector, Behaviour Change, Mental Health, Competitions

\section{INTRODUCTION}

Fitness apps are fitness-oriented platforms meant for promoting healthy living. We see how much focus has been given upon the fitness of our physical selves. People spend hours in a gym to bring their body to desired shape, some exercise every day to remain fit, some prefer yoga, while some prefer jogging or walking in fields. Physical activities have become mandatory in our daily lives so that we can keep health issues aside. And for this reason, we've seen an emerging demand for fitness applications that people use to track their fitness progress, follow fitness rituals and exercises from online trainers, or consult experts online. You just need to show to someone that how it works and in most of the cases you'll notice that they'll change their walking habits.

But how many of us have seen mental health-related section in the fitness apps we've used so far? It's few, the reason being the exclusion of mind-related concerns that remained a taboo for long in our society. It's very recently that we've started to acknowledge mental health as part of our health movement. In 2017, 197.3 million people had mental disorders in India [1]. So, it's high time we include mental health in our fitness applications so that more people become aware of the importance of having a healthy mind along with a healthy body and the people suffering may receive help from use of such applications.

\section{CASES OF NEGATIVE EFFECTS}

\section{Problems Created by Application users}

Imagine this - It's evening and you just finished your dinner and your stomach feels heavy. Who doesn't love some nice walk after dinner to help it in digestion after all it's proven by science [2]. You decided to go out take benefit of this proven science.

Copyright: @ the author(s), publisher and licensee Technoscience Academy. This is an open-access article distributed under the terms of the Creative Commons Attribution Non-Commercial License, which permits unrestricted non-commercial use, distribution, and reproduction in any medium, provided the original work is properly cited 
You opened your phone to see your step target and saw you have completed 3800/10000 of your daily target. Now your nice walk became athlete training which is by the way harmful for your body [3]. Sweaty and tired you go to bed happily enjoying your feeling of achievement. By the way there's a good chance that you'll notice problems in your bowel movement the next day.

\section{Problems created by Application Manufacturers}

Who doesn't like winning a competition or feeling superior to people around? Well some Application Manufacturers are harvesting this feeling of people by giving them a platform to compete even in number of steps they have taken in the month and there are a lot of people who put their effort in winning these and cover more than 35000 steps per day regardless of the fact that excessive exercise can affect their health negatively[4].

\section{Problems Caused by Terrain}

Step value for a person living in a hilly area is different than a person living in plains. No matter if it's going downhill or uphill, the calories burnt are more than walking on plain surface. Many apps include increase and decrease in height and it is very helpful in keeping track of exercises. However, step counter still tends to work as normal in these situations and if people try to complete their target, they'll tend to over exercise which is an irregularity and in terms of exercises, irregularity is not a good thing and it can lead to some health problems like cramps.

\section{Problems Caused by Marketing}

This competition is simple but effective tool to draw people to use their applications to sell their sponsored health products. In simple terms, these companies are harvesting the people's feelings of being psychologically rewarded for their efforts. Some companies are also using reward per step method where they give coupons after you achieve fixed steps which is good if you don't start taking it as source or reducing expenditure which is why students are the prime target of these schemes. They use these discount coupons to by items they think they need but they don't because these companies give fixed options. After all, the aim of these companies is making profit.

\section{Positive Effects}

\section{Physical Exercises that bring a body-mind balance}

Physical exercises have become important for a healthy living. An exercise does not only benefit the body, but also increases blood circulation in the body which pumps good circulation of blood to the brain, hence it helps in exercise of the brain indeed. A fitness app provides for a good number of exercise tips for the users to take care of their body and indirectly, their mind. There can be a section in the app specifically aiding for exercises that are good for the brain. A healthy brain will balance both stress and comfort with ease.

\section{How these apps help in meditation}

Meditation is, no doubt, a mind booster. It's always suggested to start meditation to have a mind-body balance. A fitness app can provide for a section where the user can access calm music for meditation, a timer for the same, a section to track their meditation routine, and also a timely reminder so that the user doesn't miss out on this important exercise for a healthy mind. An eight-week study showed that a meditation style called "mindfulness meditation" significantly reduced the inflammation response caused by stress in humans [5]. Hence, a regular meditation habit will help a lot in reducing mental issues like depression, anxiety, panic, stress, hypertension, etc. and fitness apps can help in this direction. 


\section{Yoga that calms the mind}

Yoga has been a worldwide recognized Indian health philosophy that has the magic of purifying a person from within. Not only the body, it purifies the mind and soul with some basic postures and breathing techniques. A fitness app should not ignore this gem of a practice. A dedicated section that motivates people to include yoga in their daily routine should be focused upon. The breathing techniques (pranayama like anulom-vilom, kapalabhati) are scientifically known to detoxify the mind, decrease cortisol level, and increase levels of brain repairing chemical as said by Dr B N Gangadhar, Director, National Institute of Mental Health and Neurosciences (NIMHANS)[6]. This practice has worked wonders in calming the mind and boosting mental health, hence should always be included and advertised. People suffering with mental issues will find this helpful and to their rescue.

\section{Dietary assistance aimed at soothing mind}

Diet plays a significant role in physical and mental health. It is what we eat that decides how healthy we are. Just like how bad eating habits make our physical health suffer, our mind suffers along. A good eating habit for mental boost should be provided by the fitness apps so that people get dietary assistance as to what food habits should they indulge in for a healthy mind. For example, a dietary expert would recommend inclusion of almonds in one's diet as almond is said to be a mind food, food rich in antioxidant like chamomile herb which reduces anxiety, etc.

\section{Expert Assistance as to mental health}

A fitness app may have expert assistance for the users to access assistance from expert trainers, dieticians, and fitness gurus. Such apps should also include assistance from professionals like mind doctors, psychologists and psychiatrists. A person dealing with mental problems could access the app and seek assistance from such experts in relieving from the same.

Easy Tracking of hours of sleep and relaxation for healthy mind

People who are constantly stressed due to work or are facing mental health problems due to lack of sleep or relaxation, a fitness app that tracks and reminds people of their sleeping or relaxing schedule will surely help. Sleep deprivation affects one's psychological state and mental health [7]. A person may lose track of sleep due to excessive work; the app can remind the user that it's time for him sleep or relax or just take a break and exercise. Such simple add-on features such as sleep timers can bring a lot of difference in many people's lives. Also, the sleep trackers may help people set goals for their weekly sleep hours and encourage them to meet the desired sleep duration for a healthy mind.

\section{Awareness about importance of mental health and related socializing}

Not many people speak up about their mental health problems as the society hasn't been welcoming of the fact that mental issues exist. Hence, the app should create awareness about the importance of mental health by prioritizing it at par with physical health and by providing regular statistics on the same. The app can focus on encouraging users to speak up on mental health topics by providing a socializing platform in the app itself or connecting it with a social media platform so that people connect with each other sharing their problems and solutions, or just have general healthy conversations so that there is a well-knit community that will remind people suffering with mental health that they are in this together. This will help a ton in the long run.

\section{Meeting new challenges}

COVID-19 pandemic has distressed the whole world at once. People have had a disturbing year in 2020, 
and for 2021, things remain the same. With all the lockdowns, place and space restrictions, and the consequence being economy getting wrecked worldwide, people have had their share of mental stress and trauma. Also, a very recent Oxford University study has revealed that the pandemic has resulted in side-effects for the recovered patients that relates to mental health diagnoses. It has been estimated that there is a $34 \%$ chance of being diagnosed with a neurological and mental health disorder following the COVID-19 infection [8]. In such current situations, a combined effort should be made for showing people ways of keeping themselves fit, both physically and mentally. Fitness apps can take it as a responsibility to aid in their own way for people suffering from such mental disorders.

\section{CONCLUSION}

Step Detector benefits a user with good understanding and mind control. A user must know if target is lagging then try to compete target next day and don't force their body. Also, plan exercise according to own health and not get affected by these false competitions. Application manufacturers should focus on health of people rather than only promoting their apps. They can make their apps informative so that they can track exercise with most possible factors rather than giving user an option to set goal which can only be linearly completed.

\section{REFERENCES}

[1]. How much exercise is too much Matthew Thorpe, MD, PhD and Rachael Link, MS, RD Medically reviewed by Marney A. White, $\mathrm{PhD}$, MS, 12 Science-Based Benefits of Meditation, October 27, 2020.

[2]. Aastha Ahuja, How Yoga Can Improve Your Mental Health Especially During Coronavirus Pandemic, October 09, 2020
[3]. Sleep and mental health, updated March 18, 2019

[4]. Neurological and mental disorders major risks for Covid patients, finds Oxford study, The Economic Times, April 08, 2021

\section{Cite this article as :}

Nikhil Prashant, Aditya Prem Sharma, Sama Udaykiran Reddy, "Effects of Desire to Complete Daily Steps Target using Step Detectors on Physical and Mental Health", International Journal of Scientific Research in Computer Science, Engineering and Information Technology (IJSRCSEIT), ISSN : 2456-3307, Volume 7 Issue 3, pp. 33-36, May-June 2021. Available at doi : https://doi.org/10.32628/CSEIT21733 Journal URL : https://ijsrcseit.com/CSEIT21733 